\title{
Fermentation technology applied in the insect value chain: making a win-win between microbes and insects
}

\author{
L. Van Campenhout ${ }^{1,2 *}$ \\ ${ }^{1}$ KU Leuven, Department of Microbial and Molecular Systems $\left(M^{2} S\right)$, Research Group for Insect Production and Processing, \\ Geel Campus, 2440 Geel, Belgium; ${ }^{2}$ KU Leuven, Leuven Food Science and Nutrition Research Centre (LFoRCe), 3001 Leuven, \\ Belgium; leen.vancampenhout@kuleuven.be
}

(C) 2021 Wageningen Academic Publishers

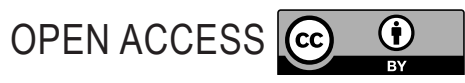

EDITORIAL

\begin{abstract}
The insect sector can benefit from applying fermentation technology as a process step at multiple stages. In the first place, fermentation of the (usually plant-based) substrate is comparable to silage applied in traditional animal husbandry and it is already applied in the insect industry. The process can enhance the digestibility of the substrate for insects, or when insects are reared on fermented substrates, their characteristics or those of the residue may be more suited for certain applications. In contrast, fermentation of the insects themselves is less well established. From the few reports available, it appears that optimalisation of the fermentation of insects, an animal-based matrix, is not evident. Fermentation can go in the wrong direction when the process conditions are not properly fined-tuned for the matrix. Nevertheless, insect fermentation deserves further exploration. The few studies available on the topic prove that fermentation can improve their taste, aroma, shelf life, digestibility and/or other characteristics, leading to new applications.
\end{abstract}

Keywords: edible insects, fermentation, substrate, ensiling, starter culture

\section{Introduction}

Fermentation is a biotechnological process in which micro-organisms are used to improve the characteristics of biomass. Stanbury et al. (2016) formulate a strict definition of fermentation as the generation of energy by micro-organisms via the catabolism (metabolic pathways for degradation) of organic compounds. They also state that in a broader context, fermentation can be considered as any process for the production of a fermentation product by the mass culture of a micro-organism. Five major groups of fermentations can be discerned: processes in which the products are microbial cells, microbial enzymes, metabolites (de novo synthesis), recombinant products, and finally fermentations for the transformation of a compound that is added (called a 'precursor') (Stanbury et al., 2016).

Another way to structure the vast range of fermentation processes is by the nature of the medium in which they are performed. Liquid state fermentation (LSF) and solid state fermentation (SSF) are the two main types, but some variations in between these two main types exist as well, such as submerged fermentations. A LSF is carried out in a liquid medium kept under controlled conditions in a bioreactor. Usually a cell suspension of a micro-organism, called 'the inoculum', is added to perform the fermentation. Most of the times, bacteria or yeasts are used as inoculum in LSF. In contrast, in SSF there is no (or not much) free water present in the biomass or medium. SSF can be performed in a dedicated bioreactor, but often the process is conducted in trays in a climate-controlled fermentation room or in heaps outside. In general, moulds are more suited as inoculum for SSF than bacteria and yeasts, since the former produce a mycelium with hyphae that easily penetrate the solid and often fibrous substrate. However, many types of SSF are spontaneous fermentations, i.e. no inoculum is added, and the fermentation is executed by the micro-organisms endogenously present in the biomass.

In the insect sector, fermentation can be a useful process step at several stages in the value chain. When preparing the substrate for feeding the insects, the substrate can be 
fermented prior to administration. In cases where waste streams from the food, horticultural or agricultural sector are used as substrate (ingredient) for insect rearing, the practices are very similar to the silage of feed, and merely involve SSF. Insect producers or companies producing insect substrates are fairly familiar with the benefits of and methods for fermentation. After the rearing phase, the insects obtained can be subjected to a fermentation process, but the application of fermentation at this stage is much less documented and applied so far. Finally, also the insect residue, or frass, may well be fermented as a processing step to reduce pathogens and improve its chemical composition, in order to make the material suitable as soil improver or fertiliser. To the author's knowledge, this application is not yet reported in literature and will not be described further. Below, first the state of the art of substrate fermentation and then of insect fermentation is described in more detail.

\section{Fermentation of the substrate}

There are a number of reasons why insect (feed) producers prefer to ferment substrate ingredients or the complete mixture prior to feeding it to the insects. Similar as to silage of feeds for traditional farm animals, increasing the shelf life of the substrate (ingredient) can be the main objective. Waste streams such as fruit and vegetable by-products, residues from cereal processing and food waste are highly perishable due to mould and/or bacterial growth. Insect producers often need to store large batches that cannot be fed immediately to the insects and hence they need to apply an economically feasible preservation technique that maintains the nutritional quality of the biomass, yet at the same time limits microbial growth. Rapid generation of anaerobic conditions in the fermenting mass is a prerequisite for a successful fermentation product. If, in addition, the conditions of the biomass with respect to dry matter and soluble carbohydrate content are suitable for the growth of micro-organisms capable to ferment (such as lactobacilli), then the $\mathrm{pH}$ of the biomass will decrease rapidly during fermentation. A substantial $\mathrm{pH}$ reduction within the first hours of the process impedes spoilage organisms and pathogens to grow. Once fermented, the low pH obtained (typically between 4 and 5) will prevent growth of spoilage and pathogenic micro-organisms, the material can be stored for weeks or months, and it is of good nutritional and microbiological quality upon feeding. Examples can be found in the insect industry of companies that ferment substrate (ingredients), but no information is available in the scientific literature.

Silage of (typically fibrous) biomass is already long known to increase digestibility of the material when fed to traditional farm animals, as illustrated for instance by Aksu et al. (2004) and Nkosi et al. (2011). Likewise, improvement of digestibility of waste streams can be a reason to ferment biomass prior to administration to insects. Kuttiyaveetil et al. (2018) demonstrated an improved growth performance of black soldier fly larvae (BSFL, Hermetia illucens) on borage and flaxseed meals after SSF with Lactobacillus plantarum or Aspergillus niger alone and in combination. While it is plausible that much more agricultural byproducts can be upgraded with respect to digestibility and nutritional value before feeding to insects, again information is scarce in literature. Distinction has to be made between fermentation of the substrate as a pretreatment before feeding, as discussed here, and another practice of supplementing probiotic micro-organisms during rearing to improve insect growth (not discussed here). The latter practice is more documented than substrate fermentation prior to administration. Research on in vitro fermentation of waste streams valuable for insect feeding can yield data that support the prediction of silage digestibility for insects in the same way as for other animal species, e.g. by Jones et al. (1980).

Most reports on fermentation as a substrate pre-treatment study the process as a means to improve an end product after insect rearing, which is typically the insect as such, but the residue is another end product. Li et al. (2015), Mohd-Noor et al. (2017) and Wong et al. $(2019,2020)$ all studied SSF of the substrate prior to feeding it to BSFL, to increase their protein and lipid content for subsequent insect protein and biodiesel production. Li et al. (2015) studied SSF of corncob and the other authors studied SSF of coconut endosperm waste. In general, the carbohydrates in these streams are rapidly hydrolysed during fermentation, thereby generating organic acids and other compounds that are metabolised into lipids and proteins by the larvae. Howdeshell and Tanaka (2018) succeeded to improve glucose recovery from the residue obtained after cultivation of BSFL on distiller's dried grains with solubles (DDGS), by fermenting the DDGS prior to rearing the larvae on it. As a solution to upgrade maize straw and to use it as fertiliser, Gao et al. (2019) worked on the bioconversion of the biomass by BSFL. They showed that conversion of maize straw that was fermented with Aspergillus oryzae before feeding to the larvae was better than conversion of unfermented straw.

While not (yet?) being demonstrated in literature, it is thinkable that fermentation of the substrate can prevent or reduce growth of pathogens, both entomopathogens as well as human pathogens, due to the low $\mathrm{pH}$ and the other antimicrobial effects of compounds such as organic acids generated during fermentation. Feeding 'healthy' substrates will yield 'healthy' insects, if contamination via other routes during rearing can be avoided. In this way, fermentation can contribute to insect disease prevention and microbiological safety of the end product. 


\section{Fermentation of insects}

When insects are subjected to fermentation, they are either fermented as a mixture with a cereal flour or as the sole major ingredient. Klunder et al. (2012) were the first to report on the possibility to ferment food containing insects, and more specifically yellow mealworms (Tenebrio molitor). The paper is still highly cited as it is the first to point to the possibility of fermentation for insects. However, what they actually fermented was a dough prepared from a flour originating from a mixture of sorghum kernels and roasted mealworms at ratios of 90:10 and 80:20. No starter cultures were added, but a natural lactic acid fermentation was achieved via backslopping, a process in which a small part of a fermented batch is used to inoculate the following batch. The authors concluded that insects can be used for protein enrichment of fermented food.

Later, other examples appeared where insects were combined with a cereal flour for fermentation purposes. Mouritsen et al. (2017) produced an insect sauce for seasoning, based on wax moth larvae (Galleria mellonella) or grasshoppers (Locusta migratoria), each combined with koji produced from pearl barley. Koji is in itself a fermented product - typically a cereal fermented with a mould such as A. oryzae - that is used as inoculum in the production soy sauce and related foods. Likewise, Cho et al. (2018) fermented a mixture of yellow mealworm larvae, roasted rice flour and koji to obtain an insect sauce. The two aforementioned fermentations had as main objective to generate taste compounds, like umami. SSF of whole or chopped larvae, combined with barley meal in different ratios, was performed without starter addition by Kube et al. (2019). Here, the aim was not to increase taste, but rather shelf life. The authors state that the addition of the water-soluble carbohydrates to BSFL was necessary to allow a lactic acid fermentation. In line with that, Mouritsen et al. (2017) point to the difference between fermenting plant-based and animal-based materials, including insects. The former contain substantial quantities of soluble carbohydrates as fermentation substrate for bacteria and/ or yeasts inoculated or naturally present, to be metabolised into organic acids and/or ethanol. Pure animal-based matrices hardly contain those carbohydrates, causing fermentation potentially to be hazardous, as the growth of and $\mathrm{pH}$ reduction by beneficial organisms may be slow, thus allowing growth of pathogens.

Therefore, while mixing insects with cereals seems to be a good practice to ferment them, the question arises whether 'pure' insects can be fermented. For blanched yellow mealworms, it has been demonstrated that fermentation is possible with certain meat starter cultures, at least when a number of conditions are met (Borremans et al., 2018, 2019, 2020a,b; De Smet et al., 2019). First of all, the larvae need to be pulverised into a fine paste. If not, the fermentation goes wrong with the development of a very repulsive, 'rotten' odour. Possibly, the starter cannot access the proteins within the exoskeleton for breakdown, and bacteria still present in the gut after blanching are metabolically active causing putrefaction. In addition, the fermentations are possible after addition of salt (to inhibit the background microbiota) and glucose (to provide substrate to the meat starter). The most important result of the fermentations in the aforementioned reports was that the mealworm paste had a significantly increased shelf life, even longer than when the paste was supplemented with traditional meat preservatives rather than being fermented (Borremans et al., 2020b).

BSFL have also been fermented as 'pure' insect. In a project report, Mogodiniyai Kasmaei (2018) explain how they tried to ferment gently crushed larvae without starter, but with the addition of $\mathrm{NaCl}$ or a mixture of sugars or a mixture of organic acids. None of the processes led to an acceptable fermentation quality, as they observed an insufficient $\mathrm{pH}$ reduction, high fermentation losses as $\mathrm{CO}_{2}$ and a bad odour, likely pointing towards unwanted activity of clostridia. The larvae were not blanched, and therefore samples likely contained a vast background microbiota, including also unwanted organisms. No starter culture was used, and so there was no control of the microbial dynamics to drive the fermentation in the good direction. The crushing may have been insufficient, preventing access for beneficial organisms to metabolisable compounds. And rather than adding salt or sugars or acids, a combination of these compounds may be necessary, as they have each a specific mode of action to contribute to a good fermentation. Even though these fermentation experiments failed, the publication of such 'negative' results is very important to move forward (Mehta, 2019) and to come to good insect fermentation practices. However, even if a paste is produced from BSFL and if a starter, salt and glucose are all added, then the $\mathrm{pH}$ reduction obtained is not so pronounced as for mealworms. This is a conclusion from our own research (publication in preparation). Likely, insects vary in their fermentability and the conditions for fermentation, including the starter, need to be optimised for each individual insect species. This is not surprising, as insect species differ in their chemical and microbiological composition (Rumpold and Schlüter, 2013).

Some authors try fermentation also as way to improve digestibility of BSFL. Nafisah et al. (2019) fermented BSFL with Bacillis subtilis and concluded that their treatment reduced chitin. It was not mentioned whether the larvae were fermented as a whole, or after chopping or grinding. Mulyono et al. (2019) fermented autoclaved BSFL meal with Trichoderma and found this treatment to reduce both in vitro and in vivo dry matter digestibility in quails. 
A very peculiar application of insect fermentation was presented by Cho et al. (2019). They performed SSF with dried, crushed and then autoclaved mulberry silkworm larvae (Bombyx mori) with Aspergillus kawachii as inoculum. The fungus hydrolysed lipids in the larvae. The fatty acids generated in this way inhibited proliferation of HepG2 human hepatocellular carcinoma cells and induced apoptosis in these cells. The extract of the fermented larvae was suggested to be a natural medicine in the treatment of liver cancer.

Optimising a fermentation process requires the fine-tuning of a range of process conditions, such as temperature, fermentation time, the use of additives (type and dose rate) and the selection of a starter culture, if applied. Also pre-treatments, such as blanching or other heat treatments, and pulverisation can have a large impact on fermentability. These degrees of freedom should all be aligned with each other and with the chemical and microbiological composition of the specific insect to be fermented. The optimisation work is normally done first at laboratory scale and the most interesting set of process parameters is then used to scale-up the process. Scaling-up of a fermentation can be done stepwise with bioreactors of increasing volumes, over pilot scale to industrial scale. All applications mentioned before were only described in literature at laboratory scale. Therefore, quite some research is still to be done on the upscaling of insect fermentations with typical hurdles to be taken, such as for instance the accomplishment of proper agitation at large scale.

\section{Conclusions}

For fermentation of substrates for insect rearing (i.e. mostly plant-based material), knowledge can be found in ensiling classical crops. Extrapolation of these practices to the typical waste streams is relatively straightforward. In contrast, fermentation of insects (i.e. animal-based material) is more critical and not all trials are an (immediate) success. Fermentation is sometimes considered as an 'art', where the 'art' comes down to creating conditions that allow beneficial organisms, either added or not, to do their job and that inhibit activity of unwanted organisms. This is particularly true for insects, as they contain a rich microbiota, that is not always easy to silence during fermentation. Nevertheless, fermentation of insects is worthwhile to explore further as it may lead to new and exciting valorisation opportunities for insects.

\section{References}

Aksu, T., Baytok, E. and Bolat, D., 2004. Effects of a bacterial silage inoculant on corn silage fermentation and nutrient digestibility. Small Ruminant Research 55(1-3): 249-252. https://doi.org/10.1016/j. smallrumres.2003.12.012
Borremans, A, Bußler, S., Sagu, T.S., Rawel, H.M., Schlüter, O. and Van Campenhout, L., 2020a. Effect of blanching plus fermentation on selected functional properties of mealworm (Tenebrio molitor) powders. Foods 9(7): 917. https://doi.org/10.3390/foods9070917

Borremans, A., Crauwels, S., Vandeweyer, D., Smets, R., Verreth, C., Van der Borght, M., Lievens, B. and Van Campenhout, L., 2019. Comparison of six commercial meat starter cultures for the fermentation of yellow mealworm (Tenebrio molitor) paste. Microorganisms 7: 540. https://doi.org/10.3390/ microorganisms7110540

Borremans, A., Lenaerts, S., Crauwels, S., Lievens, B. and Van Campenhout, L., 2018. Marination and fermentation of yellow mealworm larvae (Tenebrio molitor). Food Control 92: 47-52. https:// doi.org/10.1016/j.foodcont.2018.04.036

Borremans, A., Smets, R. and Van Campenhout, L., 2020 b. Fermentation versus meat preservatives to extend the shelf life of mealworm (Tenebrio molitor) paste for feed and food applications. Frontiers in Microbiology 11: 1510. https://doi.org/10.3389/ fmicb.2020.01510

Cho, H.D., Min, H.J., Won, Y.S., Ahn, H.Y., Cho, Y.S. and Seo, K.I., 2019. Solid state fermentation process with Aspergillus kawachii enhances the cancer-suppressive potential of silkworm larva in hepatocellular carcinoma cells. BMC Complementary and Alternative Medicine 19(1): 241. https://doi.org/10.1186/s12906-019-2649-7

Cho, J.H., Zhao, H.L., Kim, J.S., Kim, S.H. and Chung, C.H., 2018. Characteristics of fermented seasoning sauces using Tenebrio molitor larvae. Innovative Food Science and Emerging Technologies 45: 186-195. https://doi.org/10.1016/j.ifset.2017.10.010

De Smet, J., Lenaerts, S., Borremans, A., Scholliers, J., Van der Borght, M. and Van Campenhout, L., 2019. Stability assessment and laboratory scale fermentation of pastes produced on a pilot scale from mealworms (Tenebrio molitor). LWT - Food Science and Technology 102: 113-121. https://doi.org/10.1016/j.lwt.2018.12.017 Gao, Z., Wang, W., Lu, X., Zhu, F., Liu, W., Wang, X. and Lei, C., 2019. Bioconversion performance and life table of black soldier fly (Hermetia illucens) on fermented maize straw. Journal of Cleaner Production 230: 974-980. https://doi.org/10.1016/j. jclepro.2019.05.074

Howdeshell, T. and Tanaka, T., 2018. Recovery of glucose from dried distiller's grain with solubles, using combinations of solid-state fermentation and insect culture. Canadian Journal of Microbiology 64(10): 706-715. https://doi.org/10.1139/cjm-2018-0042

Jones, G.M., Larsen, R.E. and Lanning, N.M., 1980. Prediction of silage digestibility and intake by chemical analyses or in vitro fermentation techniques. Journal of Dairy Science 63(4): 579-586. https://doi. org/10.3168/jds.S0022-0302(80)82974-2

Klunder, H.C., Wolkers-Rooijackers, J., Korpela, J.M. and Nout, M.J.R., 2012. Microbiological aspects of processing and storage of edible insects. Food Control 26(2): 628-631. https://doi.org/10.1016/j. foodcont.2012.02.013

Kube, K., Resch, R. and Gierus, M., 2019. Ensiling Hermentia illucens larvae for storage purposes. In: Piofcyzk, T. and Schlüter, O. (eds.) Book of abstracts of the INSECTA Congress. 5-6 September 2019. Potsdam, Germany, pp. 102. 
Li, W., Li, Q., Zheng, L., Wang, Y., Zhang, J., Yu, Z. and Zhang, Y., 2015. Potential biodiesel and biogas production from corncob by anaerobic fermentation and black soldier fly. Bioresource Technology 194: 276-282. https://doi.org/10.1016/j.biortech.2015.06.112

Mehta, D., 2019. Highlight negative results to improve science. Nature Comments \& Opinion. https://doi.org/10.1038/d41586-019-02960-3

Mogodiniyai Kasmaei, K., 2018. Ensiling as a method for storage and processing of black soldier fly larvae for use as animal feed. Research report from the Swedish Energy Agency. Available at: https://www. energimyndigheten.se/forskning-och-innovation/projektdatabas/ sokresultat/GetDocument/?ID=108894ad-0a8c-41b8-a119-acc ea4047c9e\&documentName=Scientific_report_EM_rev.pdf.pdf

Mohd-Noor, S.N., Wong, C.Y., Lim, J.W., Mah-Hussin, M.I.A., Uemura, Y., Lam, M.K., Ramli, A., Bashir, M.J.K., Tham, L., 2017. Optimization of self-fermented period of waste coconut endosperm destined to feed black soldier fly larvae in enhancing the lipid and protein yields. Renewable Energy 111: 646-654. https://doi. org/10.1016/j.renene.2017.04.067

Mouritsen, O.G., Duelund, L., Calleja, G. and Frøst, M.B., 2017. Flavour of fermented fish, insect, game, and pea sauces: Garum revisited. International Journal of Gastronomy and Food Science 9: 16-28. https://doi.org/10.1016/j.ijgfs.2017.05.002

Mulyono, M., Yunianto, V.D., Suthama, N. and Sunarti, D., 2019. The effect of fermentation time and Trichoderma levels on digestibility and chemical components of black soldier fly (Hermetia illucens) larvae. Livestock Research for Rural Development 31: 150.
Nafisah, A., Nahrowi, Mutia, R. and Jayanegara, A., 2019. Chemical composition, chitin and cell wall nitrogen content of black soldier fly (Hermetia illucens) larvae after physical and biological treatment. IOP Conference Series: Materials Science and Engineering 546(4): 042028. https://doi.org/10.1088/1757-899X/546/4/042028

Nkosi, B.D., Meeske, R., Langa T. and Thomas, R.S., 2011. Effects of bacterial silage inoculants on whole-crop maize silage fermentation and silage digestibility in rams. South African Journal of Animal Science 41(4): 350-359. https://doi.org/10.4314/sajas.v41i4.5

Rumpold, B.A. and Schlüter, O.K., 2013. Nutritional composition and safety aspects of edible insects. Molecular and Nutrition and Food Research 67: 802-823. https://doi.org/10.1002/mnfr.201200735

Stanbury, P., Whitaker, A. and Hall, S., 2016. Principles of fermentation technology. Elsevier Science \& Technology, Oxford, UK, 824 pp.

Wong, C.Y., Lim, J.W., Chong, F.K., Lam, M.K., Uemura, Y., Tan, W.N., Bashir, M.J.K., Lam, S.M., Sin, J.C. and Lam, S.S., 2020. Valorization of exo-microbial fermented coconut endosperm waste by black soldier fly larvae for simultaneous biodiesel and protein productions. Environmental Research 185: 109458. https://doi.org/10.1016/j. envres.2020.109458

Wong, C.Y., Rosli, S.S., Uemura, Y., Ho, Y.C., Leejeerajumnean, A., Kiatkittipong, W., Cheng, C.K., Lam, M.K. and Lim, J.W., 2019. Potential protein and biodiesel sources from black soldier fly larvae: Insights of larval harvesting instar and fermented feeding medium. Energies 12(8): 1570. https://doi.org/10.3390/en12081570 
